Article

\title{
A Layer-Dependent Analytical Model for Printability Assessment of Additive Manufacturing Copper/Steel Multi-Material Components by Directed Energy Deposition
}

\author{
Wenqi Zhang ${ }^{1}$, Baopeng Zhang ${ }^{1}$, Haifeng Xiao ${ }^{1}$, Huanqing Yang ${ }^{2}$, Yun Wang ${ }^{2}$ and Haihong Zhu ${ }^{1, *}$ \\ 1 Wuhan National Laboratory for Optoelectronics, Huazhong University of Science and Technology, \\ Wuhan 430074, China; vinkyz@hust.edu.cn (W.Z.); zhangbp@hust.edu.cn (B.Z.); xiaohaif@hust.edu.cn (H.X.) \\ 2 XI'AN Space Engine Company Limited, Xi'an 710100, China; 13991882146@163.com (H.Y.); \\ wyun7103@163.com (Y.W.) \\ * Correspondence: zhuhh@mail.hust.edu.cn; Tel.: +86-27-87544774
}

Citation: Zhang, W.; Zhang, B.; Xiao, H.; Yang, H.; Wang, Y.; Zhu, H. A Layer-Dependent Analytical Model for Printability Assessment of Additive Manufacturing Copper/Steel Multi-Material Components by Directed Energy Deposition. Micromachines 2021, 12, 1394. https://doi.org/10.3390/ mi12111394

Academic Editor:

Nam-Trung Nguyen

Received: 12 October 2021

Accepted: 10 November 2021

Published: 13 November 2021

Publisher's Note: MDPI stays neutral with regard to jurisdictional claims in published maps and institutional affiliations.

Copyright: (c) 2021 by the authors. Licensee MDPI, Basel, Switzerland. This article is an open access article distributed under the terms and conditions of the Creative Commons Attribution (CC BY) license (https:// creativecommons.org/licenses/by/ $4.0 /)$.

\begin{abstract}
Copper/steel bimetal, one of the most popular and typical multi-material components $(\mathrm{MMC})$, processes excellent comprehensive properties with the high strength of steel and the high thermal conductivity of copper alloy. Additive manufacturing (AM) technology is characterized by layer-wise fabrication, and thus is especially suitable for fabricating MMC. However, considering both the great difference in thermophysical properties between copper and steel and the layer-based fabrication character of the AM process, the optimal processing parameters will vary throughout the deposition process. In this paper, we propose an analytical calculation model to predict the layer-dependent processing parameters when fabricating the $07 \mathrm{Cr} 15 \mathrm{Ni} 5$ steel on the $\mathrm{CuCr}$ substrate at the fixed layer thickness $(0.3 \mathrm{~mm})$ and hatching space $(0.3 \mathrm{~mm})$. Specifically, the changes in effective thermal conductivity and specific heat capacity with the layer number, as well as the absorption rate and catchment efficiency with the processing parameters are considered. The parameter maps predicted by the model have good agreement with the experimental results. The proposed analytical model provides new guidance to determine the processing windows for novel multi-material components, especially for the multi-materials whose physical properties are significantly different.
\end{abstract}

Keywords: directed energy deposition; additive manufacturing; bimetal; analytical model; printability maps

\section{Introduction}

Multi-material components (MMC), such as gradient materials, dissimilar joints, and sandwich structure materials, are characterized by spatial composition variation in one or more directions [1]. Due to their unique properties with progressive change in performance and function, MMC has gained notable attention and has been widely used in many fields such as electrical and aerospace over the past few decades [2]. Copper/steel bimetal, one of the most popular and typical MMC, processes excellent comprehensive properties with the high strength of steel and the high thermal conductivity of copper alloy. Because of its excellent properties, copper/steel has found its applications in the power generation, transmission, and die-casting industries [3]. Despite its attractive function and thermophysical properties, fabricating copper/steel MMC is still challenging due to its heterogeneous materials and thermophysical properties [4].

Additive manufacturing (AM) has been identified as an innovative manufacturing method that enables the build-up of components with complex geometries directly from 3D models. AM technology is characterized by the layer-wise fabrication of a part through selectively adding and melting material. It provides many advantages, including high manufacturing freedom, excellent part performance, and high production efficiency [5]. Due to the layer-wise process approach, AM is especially suitable for fabricating MMC [6,7]. 
With the growing requirement in industrial applications, many researchers are committed to using AM methods to fabricate MMC. The two most popular AM technologies, directed energy deposition (DED) [8,9] and powder bed fusion (PBF) $[10,11]$, have been widely investigated to fabricate the single material including copper alloys [12-14], iron alloys [15-18], titanium alloys [19-21], aluminum alloys [22-25], and nickel alloys [26,27]. However, the AM process for heterogeneous materials is very different from that for homogeneous materials. In general, processing parameters (for example, laser power and scanning velocity) and material properties (for example, thermal conductivity, specific heat capacity, and density) influence the thermal profile and the printability of the AM process. Because effective thermal conductivity varies between layers, the processing parameters may also need to change as the deposition layer numbers increase. This phenomenon is particularly prominent for copper/steel dissimilar materials, because the thermophysical properties, such as thermal conductivity, of copper and steel differ greatly. The schematic of fabricating steel on the $\mathrm{CuCr}$ substrate is illustrated in Figure 1.

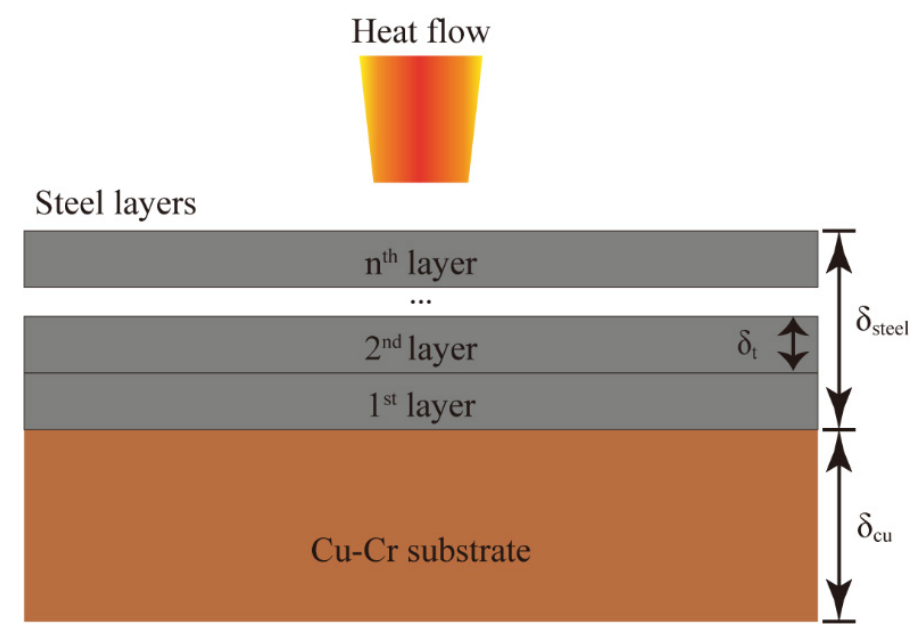

Figure 1. The schematic of fabricating the steel on the $\mathrm{CuCr}$ substrate layer by layer, where $\delta_{\mathrm{cu}}, \delta_{\text {steel }}$, and $\delta_{\mathrm{t}}$ represent the thickness of the $\mathrm{CuCr}$ substrate, the total thickness of steel coatings and the thickness of single layer steel coating, respectively.

When investigating the existing literature on AM of fabrication copper/steel or steel/copper bimetal, processing parameters optimization for every layer is absent. At present, there are mainly two methods to fabricating dissimilar materials. One common method is to use fixed parameters for steel and copper, respectively. Bai et al. [28] manufactured 316L/C52400/316L sandwich structure materials by SLM, and used the parameters for C52400 copper alloy and 316L, separately. Liu et al. [29] and Chen et al. [30] used different processing parameters for the individual alloys of steel and copper. The other common method is to utilize variable parameters, i.e., one set of parameters for the interfacial layers of copper/steel and another set of parameters for steel or copper, respectively. Chen et al. [31] optimize the interfacial layers by orthogonal experiment, and the set of parameters are fixed for steel and copper, respectively. Tan et al. [32] successfully processed steel on the copper alloy substrate by SLM, using one set of parameters for the first ten layers by remelting twice and using the optimized parameters of steel for the rest of the fabricating. In our previous work [3], the steel was built on the $\mathrm{CuCr}$ alloy substrate by DED. We optimize the parameters from one to four layers and the optimized parameters for steel are used for the rest of the layers. Based on the literature discussed above, there is currently no known work describing process-layer number relationships for fabricating copper/steel bimetal in the contest of AM.

Considering both the great difference in thermophysical properties between copper and steel and the layer-based fabrication character of the AM process, the optimal processing parameters will vary throughout the deposition process. Since there are numerous 
process variables within AM, the optimization of processing parameters for every layer is a huge amount of work [33]. Therefore, establishing a framework to implement model-based approaches to building dissimilar material parts is essential.

In this paper, we propose an analytical calculation model to predict the layer-dependent processing parameters during the fabrication of copper/steel bimetal. Specifically, the changes in effective thermal conductivity and specific heat capacity with the layer number as well as the absorption rate and catchment efficiency with the processing parameters are considered. The analytical model is established to predict molten pool temperature and thus to provide a methodology to estimate the process maps for multi-layer copper/steel bimetal dependent on the layer number. These results are compared with experimentally observed molten pool width and parameter maps for copper/steel specimens and found to have good agreement.

\section{Theoretical Modeling}

Figure 2 shows the framework for estimating the layer-dependent printability of the copper/steel bimetal. The general workflow starts with the calculations of layer-dependent thermophysical properties (the effective thermophysical properties [34]) and the processing parameters-dependent catchment efficiency [35]. Then the temperature fields and molten pool dimensions with different laser power and scanning velocity covering the processing space are obtained. The peak temperature $\left(\mathrm{T}_{\max }\right)$ and dimensions of the molten pool are subsequently used to evaluate the parameter maps and verify the model. In this study, the stainless steel is fabricated on the $\mathrm{CuCr}$ substrate, hence regions of process space with $\mathrm{T}_{\mathrm{m} \_ \text {steel }}<\mathrm{T}_{\max }<\mathrm{T}_{\mathrm{b} \_ \text {cu }}$ are recognized to be the appropriate combination of processing parameters for the first layer, and $\mathrm{T}_{\mathrm{m} \_ \text {steel }}<\mathrm{T}_{\max }<\mathrm{T}_{\mathrm{b} \_ \text {steel }}$ for the second layer and above, where $\mathrm{T}_{\mathrm{m} \_ \text {steel }}, \mathrm{T}_{\mathrm{b} \_ \text {steel }}, \mathrm{T}_{\mathrm{m} \_\mathrm{cu}}$, and $\mathrm{T}_{\mathrm{m} \_\mathrm{cu}}$ represent the melting point and boiling point of steel and $\mathrm{Cu}$, respectively. The peak temperature criterion has also been applied in the selective laser melting process [36]. Details of each step in this workflow are presented in the subsequent sections.

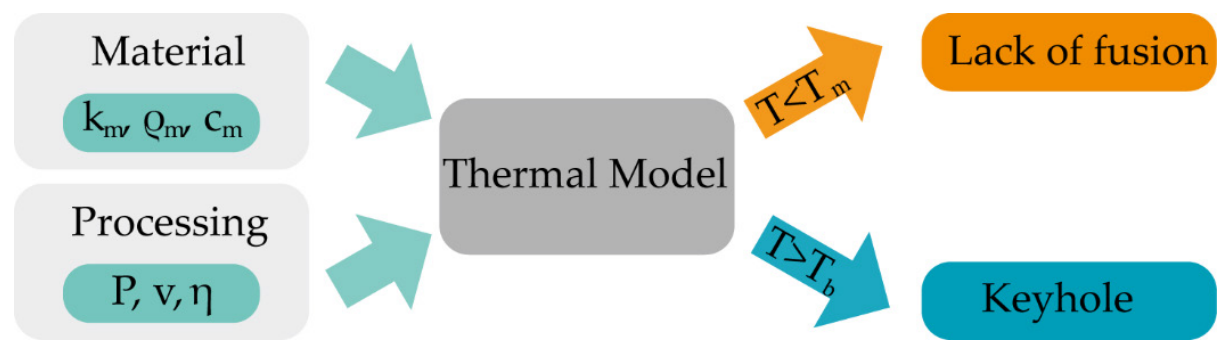

Figure 2. The framework for estimating the layer-dependent printability of the copper/steel bimetal. Processing parameters (laser power $(\mathrm{P})$, scanning velocity $(\mathrm{v})$, and powder catchment efficiency $(\eta)$ ) and layer-dependent effective material properties [35] (effective thermal conductivity $\left(\mathrm{k}_{\mathrm{m}}\right)$, effective specific heat $\left(c_{m}\right)$, and effective density $\left.\left(\rho_{m}\right)\right)$ are provided to the thermal model.

\subsection{Thermal Model}

In this framework, the temperature profile is required to calculate the temporally evolving molten pool dimensions and the temperature at the molten pool boundary (i.e., the solid-liquid interface) and the center (i.e., $\mathrm{T}_{\max }$ ). The assumption that the solidification process occurs at a constant temperature is reasonable because of the high thermal gradient and cooling rate for DED.

The Cline-Anthony model [37] is used to calculate the temperature field of the molten pool during the DED process. The Cline-Anthony model was established to analyze the thermal distribution and geometry of melting track from a moving Gaussian source on a semi-infinite substrate. Since the laser beam in this paper is small compared to the substrate, a semi-infinite geometry is a rationally good approximation. Therefore, the Cline-Anthony model is applicable in this paper. The Cline-Anthony model is beneficial 
to rapidly handle many calculations throughout the entire processing maps and has been widely used in the AM process $[38,39]$. The temperature field of the molten pool relating to the processing parameters and the thermophysical properties during DED can be calculated by the Cline-Anthony model as Equation (1):

$$
\mathrm{T}(x, y, z)=T_{0}+\frac{P_{e}}{\left(2 \pi^{3}\right)^{1 / 2} k_{m} r} \int_{0}^{\infty} \frac{1}{1+s^{2}} \exp \left\{-\frac{1}{2\left(1+s^{2}\right)}\left[\left(\frac{x}{r}+s^{2} a r\right)^{2}+\left(\frac{y}{r}\right)^{2}\right]-\frac{1}{2 s^{2}}\left(\frac{z}{r}\right)^{2}\right\} d s
$$

where $T_{0}$ is to the initial temperature of the substrate, $P_{e}$ is the total laser power absorbed by the powder and the substrate, $\mathrm{r}$ is the radius of the laser spot, $k_{m}$ is the effective thermal conductivity of the substrate, $a$ is defined as $a=\rho_{\mathrm{m}} \mathrm{c}_{\mathrm{m}} \mathrm{v} /\left(2 \mathrm{k}_{\mathrm{m}}\right)$, and $\mathrm{s}$ is defined as $s^{2}=2$ $k_{m} \mathrm{t} /\left(\rho_{\mathrm{m}} \mathrm{c}_{\mathrm{m}} \mathrm{r}\right)\left(\rho_{\mathrm{m}}, \mathrm{c}_{\mathrm{m}}, \mathrm{v}\right.$, and $\mathrm{t}$ refer to the density, specific heat capacity of the MMC, laser scanning speed, and laser scanning time, respectively).

The molten pool dimension is figured by the zone enclosed by the isosurface of the solidification temperature or melting point $\left(\mathrm{T}_{\mathrm{m}}\right)$ as illustrated in Figure 3. Figure 3a shows the 3D diagram, where SD, TD, and BD refer to scanning, transverse, and build directions, respectively. Figure $3 b$ shows the SD-TD cross-section. Then the width (W) and length (L) of the molten pool can be obtained, where $W$ equals the length of $C D$, and $L$ equals the length of $\mathrm{AB}$.

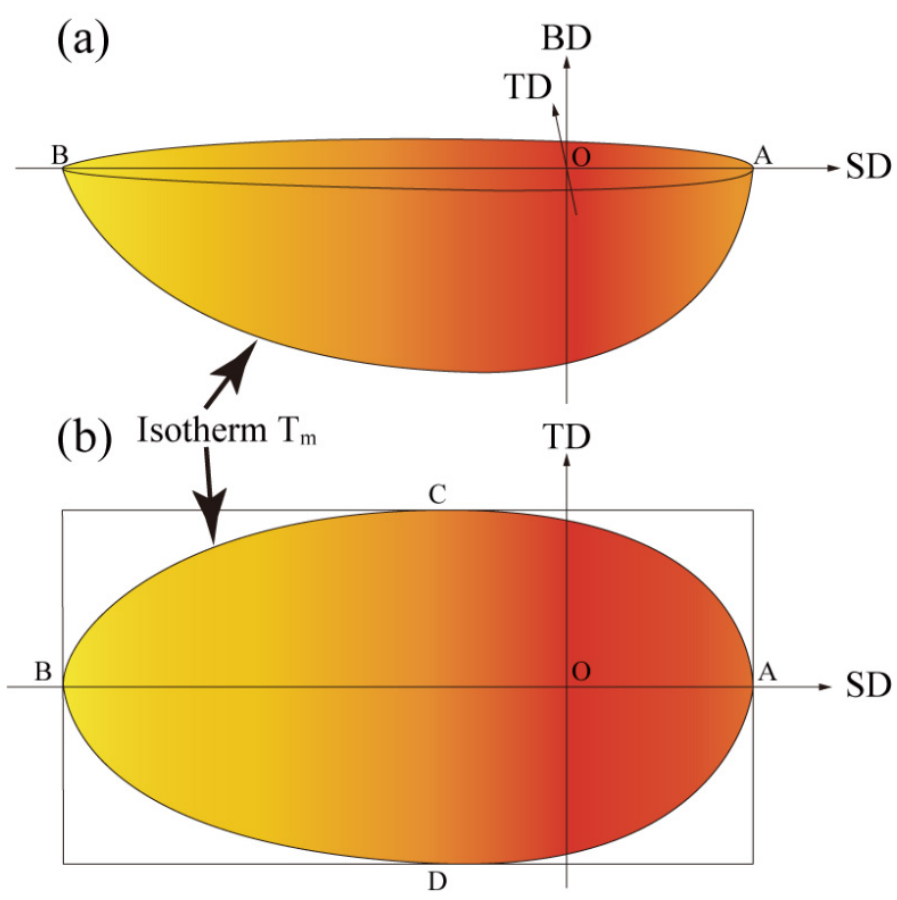

Figure 3. Schematic of the molten pool (SD, TD, BD refer to scanning, transverse, and build directions, respectively): (a) 3D diagram of the molten pool; (b) SD-TD cross-section of the molten pool.

\subsection{The Laser-Materials Interaction during the DED Process}

The typical shadow model is used for the laser-materials interaction during the DED process [38,40]. Figure 4 describes the laser-materials interaction during the DED process of fabricating steel on the copper substrate. The laser beam, metal powder, and protective gas are output from the nozzle coaxially. When traversing the powder stream, part of the laser beam interacts with the powder. Therefore, a portion of laser energy is attenuated (absorbed or scattered) by the powder, and the rest reaches the substrate surface [38]. However, due to the high reflectivity of the copper alloy substrate, a large portion of energy reaching the substrate is reflected and can be absorbed by the powder again. Finally, the energy carried by the heated powder particles partially falls into the molten pool for further melting. As the laser leaves, the molten pool cools and solidifies rapidly on the substrate 
surface to form the deposition track. The following assumptions are made for the usage of the proposed model during the DED process [40]:

(1) The laser energy attenuation is proportional to the projected area of the powder particles in the laser beam. Since the powder concentration is much smaller compared with the gas flow volume, it is reasonable to neglect the shadow between particles.

(2) The powder particles are considered homogeneous and spherical. The average diameter is used to represent the particle size. The argon gas atomized powder is used in this work, and the morphology of the powders is almost spherical from the scanning electron microscope (SEM) observation [3].

(3) The thermophysical properties of materials are regarded as constant and invariable with the temperature.

(4) The laser beam reaching the substrate is perfectly reflected upwards in the same shape as the initial beam.

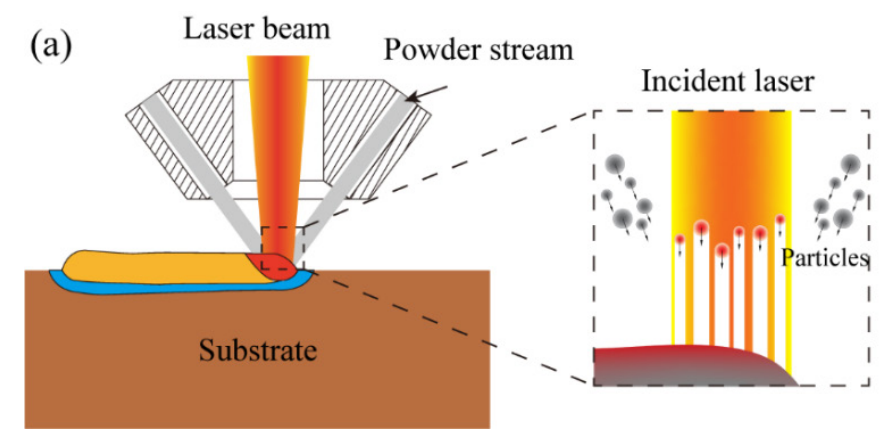

(b)

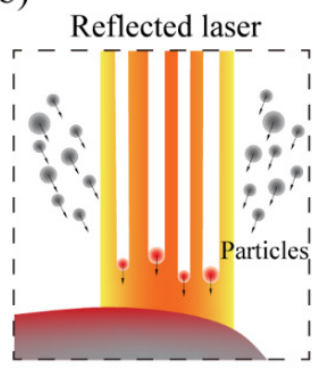

Figure 4. Schematic of the laser-material interaction: (a) the powder interacts with the incident laser; (b) the powder interacts with the reflected laser.

Based on the above assumptions, the attenuation rate of the laser energy by the powder particles can be obtained, which equals the ratio between the projected area of the powder particles and the laser beam. First, the laser beam travels through the gas-powder stream and is attenuated (absorbed or scattered) before reaching the substrate. The attenuate ratio $\beta_{\text {att }}$ can be expressed as Equation (2), which is the proportion of the projected area of the powder particles to the laser beam area [38].

$$
\beta_{a t t}=\frac{S_{p}}{S_{l}}=\frac{3 m_{p}}{2 \pi \rho_{p} r_{p} r v_{p} \cos \theta}
$$

where $S_{p}$ is the projected area of the powder particles, $S_{l}$ is the projected area of the laser beam, $m_{p}(\mathrm{~kg} / \mathrm{s})$ is the powder feeding rate, $\rho_{p}\left(\mathrm{~kg} / \mathrm{m}^{3}\right)$ is the density of the powder, $r_{p}(\mathrm{~m})$ is the average diameter of the powder particles, $r(\mathrm{~m})$ is the laser beam radius, $v_{p}(\mathrm{~m} / \mathrm{s})$ is the velocity of the powder-gas stream, and $\theta$ is the angle between the gas-powder and the horizontal. The attenuated laser power $\left(P_{a t t}\right)$ by the powder can be obtained as Equation (3):

$$
P_{a t t}=\beta_{a t t} * P
$$

where $P$ is the laser power. A portion of the attenuated laser energy is absorbed by the powder stream and delivered to the substrate when the particles enter the molten pool. The absorbed laser power by the powder stream delivered to the substrate can be expressed as Equation (4).

$$
P_{a 1}=\eta * \beta_{p} * P_{a t t}
$$

where $\beta_{p}$ is the laser absorption of the powder and $\eta$ the powder catchment efficiency. Second, the laser beam passes through the gas-powder stream and reaches the substrate. 
Then the substrate can absorb part of the laser energy $\left(P_{s}\right)$ directly based on the laser absorptivity, as is given by Equation (5):

$$
P_{s}=\beta_{s}\left(P-P_{a t t}\right)
$$

where $\beta_{s}$ is the laser absorption of the substrate. Finally, the laser beam reflected by the substrate is important for the high laser reflectivity of $\mathrm{CuCr}$ alloy substrate. Therefore, part of the reflected laser energy $\left(P_{r}\right)$ is attenuated and absorbed by the powder stream again. The powder stream transfers the absorbed energy back to the substrate $\left(P_{a 2}\right)$, as is given by Equations (6) and (7):

$$
\begin{gathered}
P_{a 2}=\eta * \beta_{a t t} * \beta_{p} * P_{r} \\
P_{r}=\left(1-\beta_{s}\right)\left(P-P_{a t t}\right)
\end{gathered}
$$

Thus, the effective laser power $\left(P_{e}\right)$, namely the total amount of laser power delivered into the molten pool by the powder stream and absorbed by the substrate, can be obtained by Equation (8):

$$
P_{e}=P_{a 1}+P_{s}+P_{a 2}
$$

\subsection{The Catchment Efficiency}

From Equations (4), (6), and (8), the powder catchment efficiency $(\eta)$ is essential for the calculation of the temperature field. According to reference [35], the defined parameter $Q$, which is related to the processing parameters and material properties, can be used to evaluate the catchment efficiency as expressed by Equation (9):

$$
Q=\frac{(P / v)^{2 / 3}}{(c \Delta T+H)^{2 / 3}}
$$

where $\Delta T, H$, and $c$ refer to the difference between the solidus temperature and ambient temperature, the latent heat of fusion, and the specific heat capacity of the alloy, respectively. For the convenience of comparing different processing parameters, the normalized value $Q^{*}$, which is expressed as $Q$ divided by $Q_{\max }$ (the maximum value for all the data used), is used to calculate the value of $\eta$ as Equation (10) [35]:

$$
\eta=-1.5\left(Q^{*}\right)^{2}+2.8\left(Q^{*}\right)-0.3
$$

\subsection{Evolution of the Substrate Laser Absorption}

The laser absorption of the substrate varies with the track and layer numbers for the heterogeneous materials. For the first track of the first layer, the laser interacts with the copper alloy substrate, and the absorption of the laser by the substrate $\left(\beta_{\mathrm{s}}\right)$ equals the copper substrate $\beta_{\mathrm{s}}=\beta_{\mathrm{cu}}$, where $\beta_{\mathrm{cu}}$ represents the laser absorption of the $\mathrm{CuCr}$ alloy. For the second track and above the first layer, part of the laser interacts with the previous steel track, and the rest with the substrate directly as shown in Figure 5. It is considered that the absorption of the substrate is the linear sum of the laser absorption rate of copper and steel and expressed as Equation (11):

$$
\beta_{s}=(1-l) * \beta_{c u}+l * \beta_{\text {steel }}
$$

where $\beta_{\text {steel }}$ represents the laser absorption of the steel, $l$ is related with the laser radius $(\mathrm{r})$, the width of the previous track (W), and the hatching space (HS) and can be expressed as Equation (12):

$$
l=\frac{r+\left(\frac{W}{2}-H S\right)}{2 r}
$$



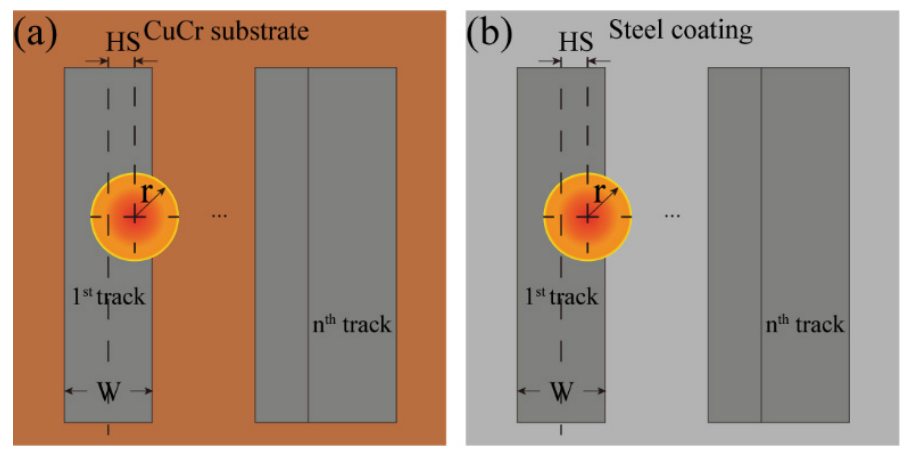

Figure 5. Evolution of the substrate laser absorption: (a) the first layer except for the first track; (b) the second layer and above.

For the second layer and above, the laser interacts with the steel coating directly, and the absorption of the laser by the substrate can be expressed as $\beta_{\mathrm{s}}=\beta_{\text {steel }}$ as shown in Figure 5b.

\subsection{Evolution of the Effective Thermophysical Properties}

The thickness of copper and steel, which is a function of the deposition layer number, determines the thermophysical properties of the copper/steel bimetal as a single component. Equation (13) gives the thermal resistance of a single material, where $\mathrm{R}, \delta, \mathrm{k}$, and $\mathrm{A}$ indicate the thermal resistance, the thickness of the material, the thermal conductivity, and the area of the cross-section that is perpendicular to the heat flow direction, respectively. The total thermal resistance $\left(R_{m}\right)$ of the MMC, as seen in Figure 1, can be represented in Equation (14). The subscript $\mathrm{m}$, steel, and cu denote the copper/steel MMC, the stainless steel, and $\mathrm{CuCr}$ alloy, respectively. If the copper/steel bimetal is treated as a single component, the theoretical effective thermal conductivity [34] $\left(k_{m}\right)$, density $\left(\rho_{m}\right)$, and specific heat capacity $\left(c_{m}\right)$ of the MMC are obtained in Equations (15)-(17) [41,42]. Where $V_{\text {steel }}^{\prime}=\frac{V_{\text {steel }}}{V_{\text {steel }}+V_{c u}}, V_{c u}^{\prime}=\frac{V_{c u}}{V_{\text {steel }}+V_{c u}}, \rho_{\text {steel }}^{\prime}=\frac{\rho_{\text {steel }}}{\rho_{m}}, \rho_{c u}^{\prime}=\frac{\rho_{c u}}{\rho_{m}}, \delta_{\text {steel }}=(\mathrm{n}-1) * \delta_{\mathrm{t}}, \mathrm{n}$ represents the layer number and $\delta_{t}$ is the layer thickness.

$$
\begin{gathered}
R=\frac{\delta}{k A} \\
R_{m}=\frac{\delta_{\text {steel }}}{k_{\text {steel }} A}+\frac{\delta_{c u}}{k_{c u} A} \\
k_{m}=\frac{\delta_{\text {steel }}+\delta_{c u}}{\frac{\delta_{\text {steel }}+\frac{\delta_{C u}}{k_{\text {Steel }}}}{k_{c u}}} \\
\rho_{m}=\rho_{\text {steel }} V_{\text {steel }}^{\prime}+\rho_{c u} V_{c u}^{\prime} \\
c_{m}=\rho_{\text {steel }}^{\prime} V_{\text {steel }}^{\prime} c_{\text {steel }}+\rho_{c u}^{\prime} V_{c u}^{\prime} c_{c u}
\end{gathered}
$$

Table 1 provides the values of the single metal thermophysical properties of $\mathrm{CuCr}$ and the self-developed martensite stainless steel (07Cr15Ni5), respectively. Figure 6 shows the theoretically calculated layer-dependent effective thermophysical properties (effective thermal conductivity, density, and specific heat capacity) of the copper/steel bimetal according to Equations (14)-(16). 
Table 1. Thermophysical properties of $\mathrm{CuCr}$ and steel for the calculation [43-47].

\begin{tabular}{ccc}
\hline Parameters & CuCr & Steel \\
\hline Density, $\rho\left(\mathrm{kg} \mathrm{m}^{-3}\right)$ & 8.90 & 7.78 \\
Melting point, $T_{m}(\mathrm{~K})$ & 1358 & 1654 \\
Boiling point, $T_{b}(\mathrm{~K})$ & 2835 & 3086 \\
Thermal conductivity, $k\left(\mathrm{~W} \mathrm{~m}^{-1} \mathrm{~K}^{-1}\right)$ & 180 & 80 \\
Specific heat capacity, $c\left(\mathrm{~J} \mathrm{~kg}^{-1} \mathrm{~K}^{-2}\right)$ & 385 & 450 \\
Laser beam absorptivity, $\beta$ & 0.2 & 0.5 \\
\hline
\end{tabular}
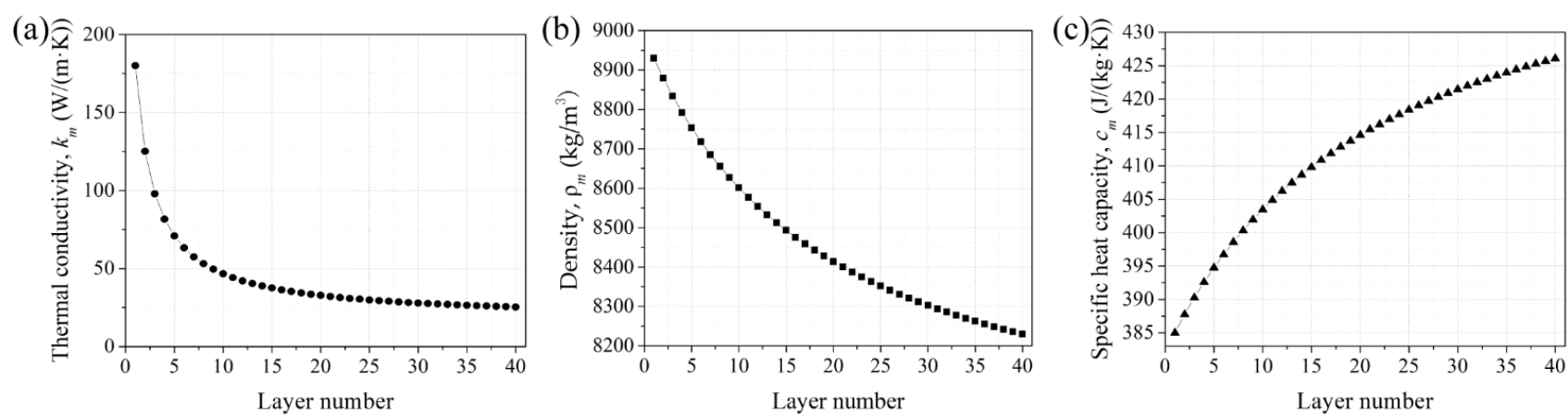

Figure 6. The calculated layer-dependent effective physical properties of the copper/steel bimetal: (a) effective thermal conductivity; (b) effective density; (c) effective specific heat capacity.

\section{Printability Predictions}

\subsection{Printability Maps for the First Layer}

During the DED process, the processing parameters such as laser power and scanning velocity determine the heat flow of laser energy to the powder and substrate and ultimately affect the temperature field. According to Equations (1) and (8), increasing laser power or decreasing scanning velocity transmits more energy to the powder and substrate. By increasing the heat input, fusion commences when the temperature of the material rises from the ambient temperature to the melting point $\left(T_{m}\right)$. Further increasing the laser energy will continue to raise the temperature to the boiling point $\left(\mathrm{T}_{\mathrm{b}}\right)$. According to reference [48], when the peak temperature $\left(T_{\max }\right)$ of the molten pool reaches $T_{b}$, the recoil pressure caused by the evaporation drives the molten pool to the keyhole mode. Therefore, the condition $\mathrm{T}_{\max }=\mathrm{T}_{\mathrm{b}}$ is identified as the keyhole mode threshold.

The printability map is determined by analyzing the temperature characteristics of the molten pool under various processing parameters. Table 2 shows the processing parameters calculated for the first layer. Figure 7 shows the peak temperature for different parameters combined with laser power and scanning velocity for the first layer. The isotherms of the melting and boiling points of copper and steel $\left(\mathrm{T}_{\mathrm{s}_{-} \mathrm{cu}}=1337 \mathrm{~K}\right.$, $\mathrm{T}_{\mathrm{s}_{\_} \text {steel }}=1654 \mathrm{~K}, \mathrm{~T}_{\mathrm{b}_{\text {c cu }}}=2835 \mathrm{~K}, \mathrm{~T}_{\mathrm{b}_{\text {ssteel }}}=3086 \mathrm{~K}$ ) are marked in Figure 7 , respectively. According to the peak temperature at the center of the molten pool, three situations can be obtained: (1) $\mathrm{T}_{\max }<\mathrm{T}_{\mathrm{s}_{\text {_steel }}}$; (2) $\mathrm{T}_{\mathrm{s}_{\text {_ssteel }}}<\mathrm{T}_{\max }<\mathrm{T}_{\mathrm{b}_{-} \text {cu }}$; (3) $\mathrm{T}_{\max }>\mathrm{T}_{\mathrm{b}_{-} \mathrm{cu}}$. For situation (1), the temperature of the molten pool cannot reach the melting point of the steel (1654 K). Therefore, no fusion will occur because of the insufficient input energy. The steel coating cannot be fabricated on the copper substrate and form a metallurgical bond. For situation (2), the molten pool temperature is in the range of $\mathrm{T}_{\mathrm{s}_{-} \text {steel }}$ and $\mathrm{T}_{\mathrm{b}_{-} \mathrm{cu}}$. Therefore, the fusion track can be obtained in the conduction mode. For situation (3), the molten pool temperature is higher than the $\mathrm{T}_{\mathrm{b}_{-} \mathrm{cu}}$, and the fusion track can be obtained in the keyhole mode. Firstly, the parameters for situation (1) are excluded because no fusion occurred between the copper substrate and steel powder. Secondly, the keyhole mode can lead to a porosity void with vapor entrapping at the bottom of the molten pool $[49,50]$ as well as a high dilution of the molten pool [51], which is not expected to produce good mechanical properties. Hence, 
the parameters for situation (3) are excluded. From the results of calculation and analysis above, situation (2) is evaluated as appropriate process maps before starting the experiments. Although the criterion of $\mathrm{T}_{\mathrm{s}_{\_} \text {steel }}<\mathrm{T}_{\max }<\mathrm{T}_{\mathrm{b}_{\mathrm{B}} \mathrm{cu}}$ may not be a precise condition, it can narrow the range of experimental parameters, and further parameters optimization can be conducted from the experiment based on the results. The peak temperature criterion has also been applied in the selective laser melting process $[36,52]$.

Table 2. Processing parameters for the first layer.

\begin{tabular}{cc}
\hline Parameters & Values \\
\hline Laser power $(\mathrm{P}, \mathrm{W})$ & $500 \sim 5000(500$ increment $)$ \\
Scanning velocity $(\mathrm{V}, \mathrm{mm} / \mathrm{min})$ & $400 \sim 2000(200$ increment $)$ \\
Hatching space $(\mathrm{HS}, \mathrm{mm})$ & 0.3 \\
Powder feeding rate $(\mathrm{g} / \mathrm{min})$ & 12 \\
Z-axis increment $(\mathrm{mm})$ & 0.3 \\
Laser spot diameter $(\mathrm{mm})$ & 1 \\
\hline
\end{tabular}

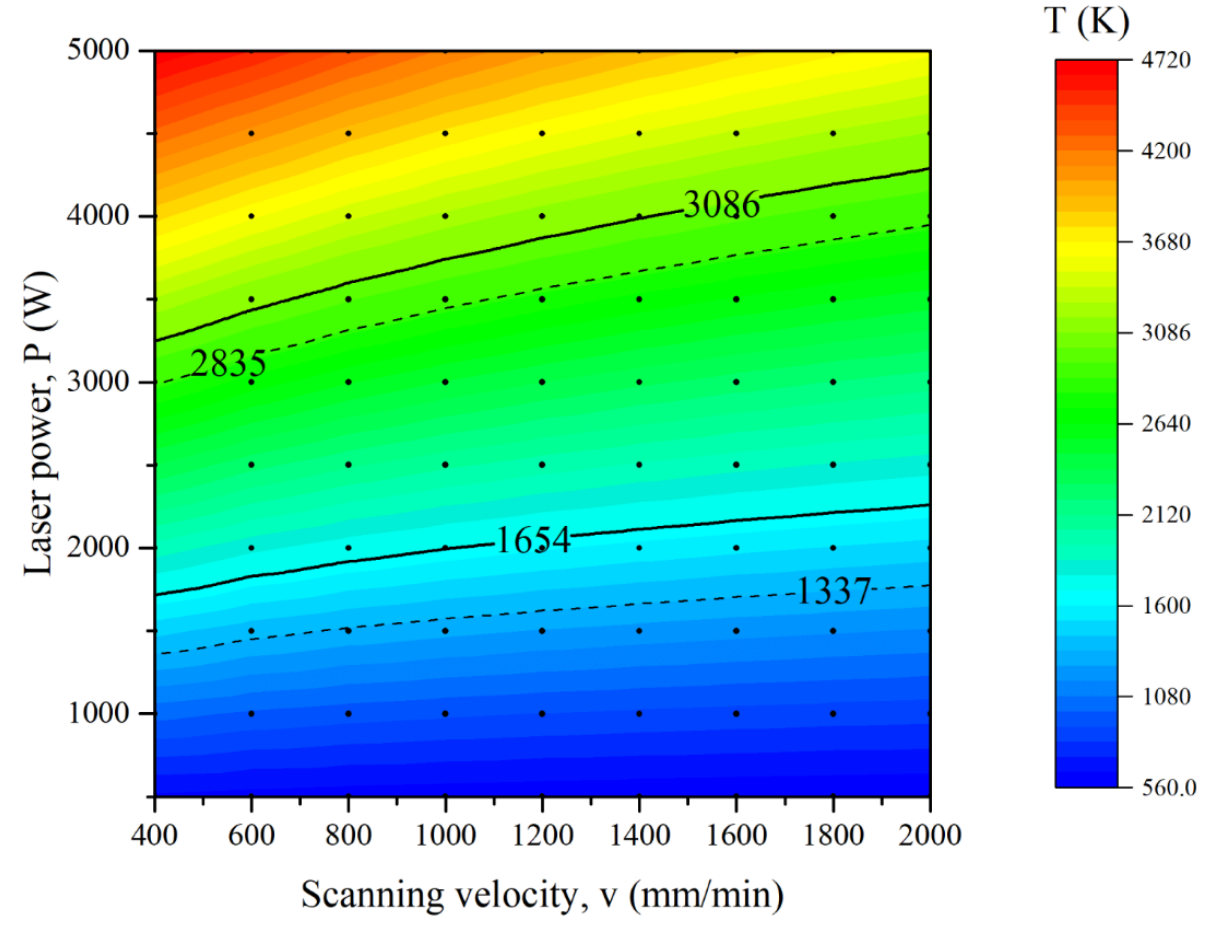

Figure 7. The peak temperature of different parameters for the first layer $\left(\mathrm{T}_{\mathrm{S}_{-} \mathrm{cu}}=1337 \mathrm{~K}\right.$, $\left.\mathrm{T}_{\mathrm{S} \_ \text {steel }}=1654 \mathrm{~K}, \mathrm{~T}_{\mathrm{b} \_\mathrm{cu}}=2835 \mathrm{~K}, \mathrm{~T}_{\mathrm{b} \_ \text {steel }}=3086 \mathrm{~K}\right)$.

\subsection{Printability Maps for Multi-Layer}

Since a layer of steel has been deposited on the copper substrate, the effective thermal conductivity, laser absorption, etc., will change significantly from the second layer. Therefore, the processing parameters will vary with the layer number. Figure 8 shows the calculated peak temperature distribution for the second to seventh layers. Similarly, the isotherms of the melting and boiling points of copper and steel are marked and different regions are labeled. As described in Figure 7, the peak temperature in the range of $\mathrm{T}_{\mathrm{s}_{-} \text {steel }}<\mathrm{T}_{\max }<\mathrm{T}_{\mathrm{b}_{-} \mathrm{cu}}$ is selected for the first layer. However, the deposited layer will be in direct contact with the steel from the second layer. Hence, the criteria for the upper limit of the peak temperature can change to the boiling point of the steel, i.e., $\mathrm{T}_{\max }<\mathrm{T}_{\mathrm{b}_{-} \text {steel }}$. Apparently, for a certain parameter combination with laser power and scanning velocity, the peak temperature increases with the layer number. Namely, the process maps move to- 
wards the low energy region and the printability maps become narrow. This phenomenon is more pronounced for the 10th to 40th layers, as is shown in Figure 9.
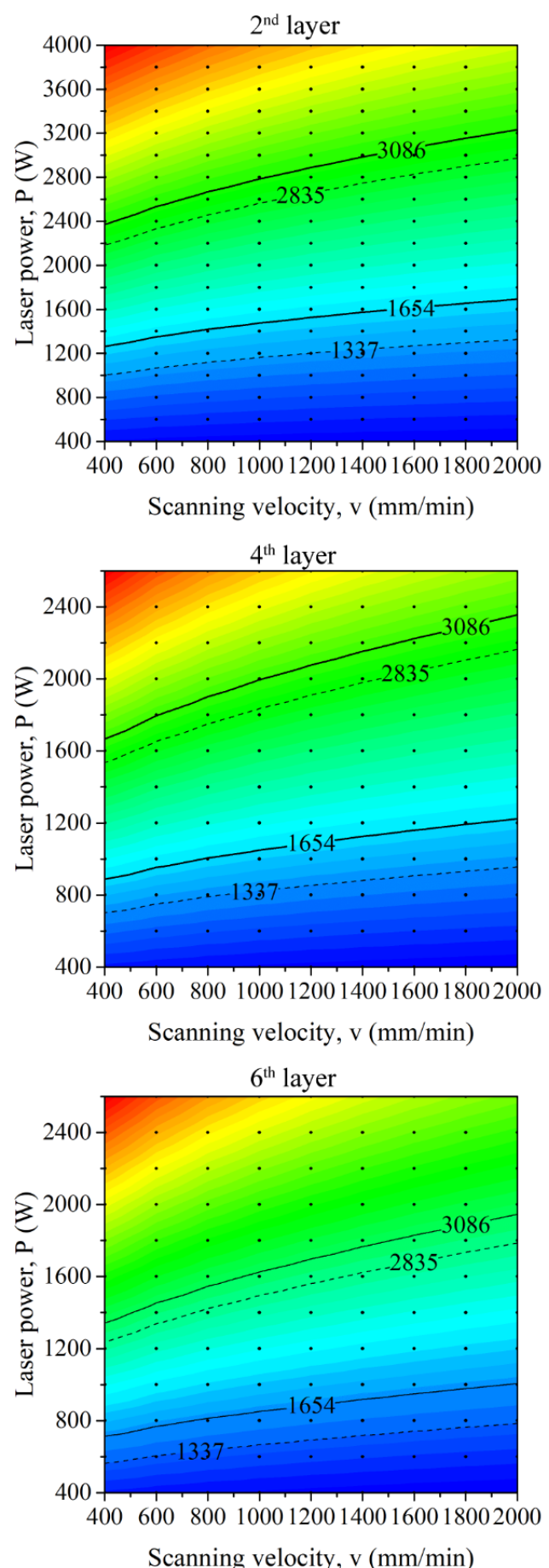
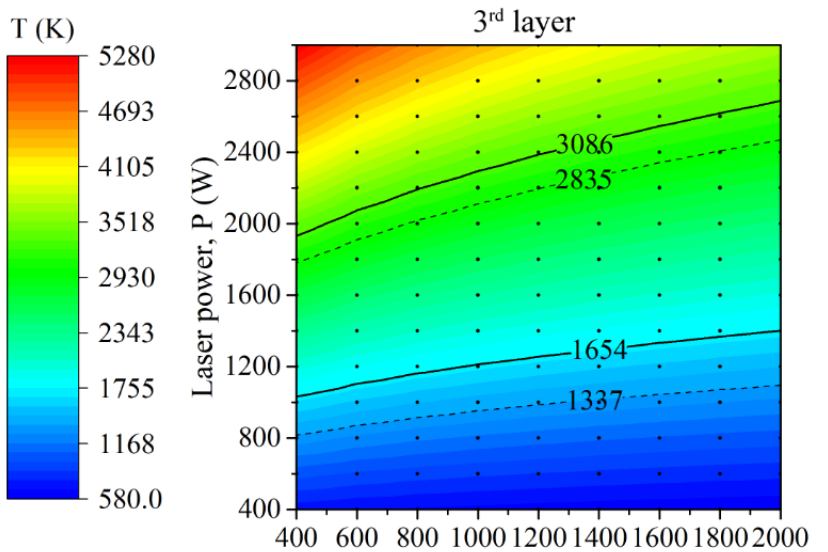

Scaning velocity, $\mathrm{v}(\mathrm{mm} / \mathrm{min})$
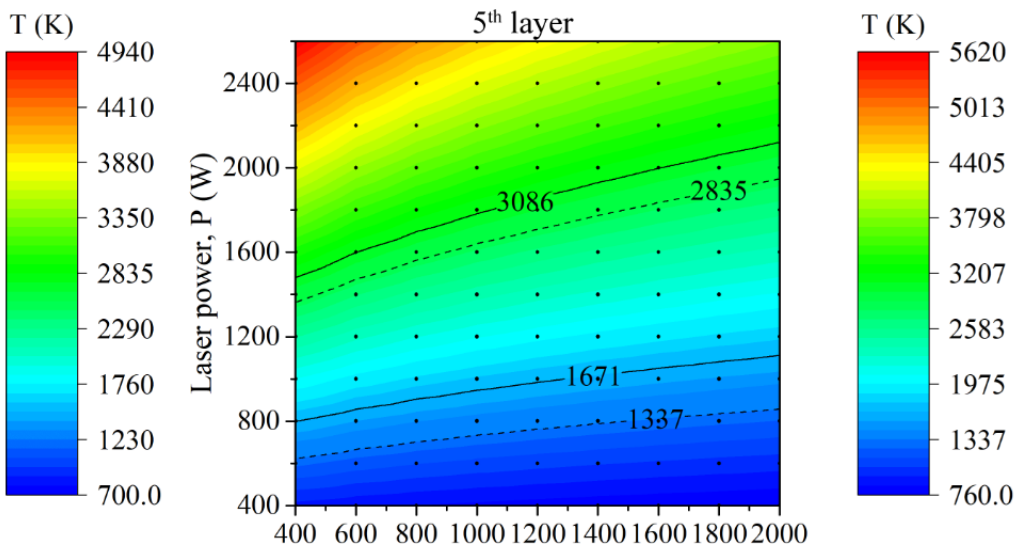

Scanning velocity, $\mathrm{v}(\mathrm{mm} / \mathrm{min})$
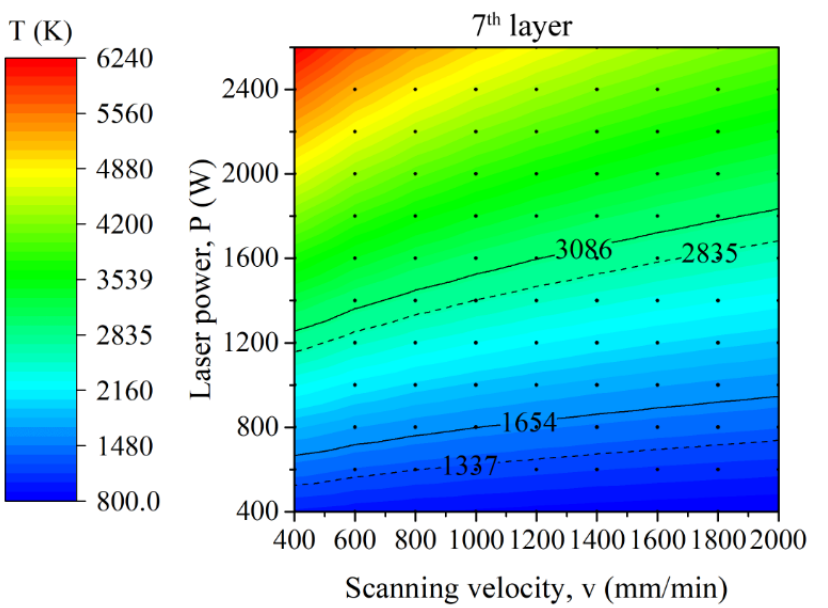

$\mathrm{T}(\mathrm{K})$

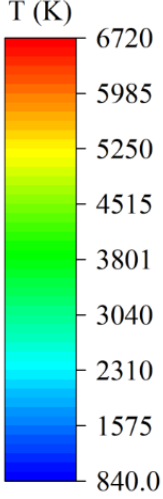

840.0

Figure 8. The peak temperature of different parameters for the 2 nd to 7 th layers. 

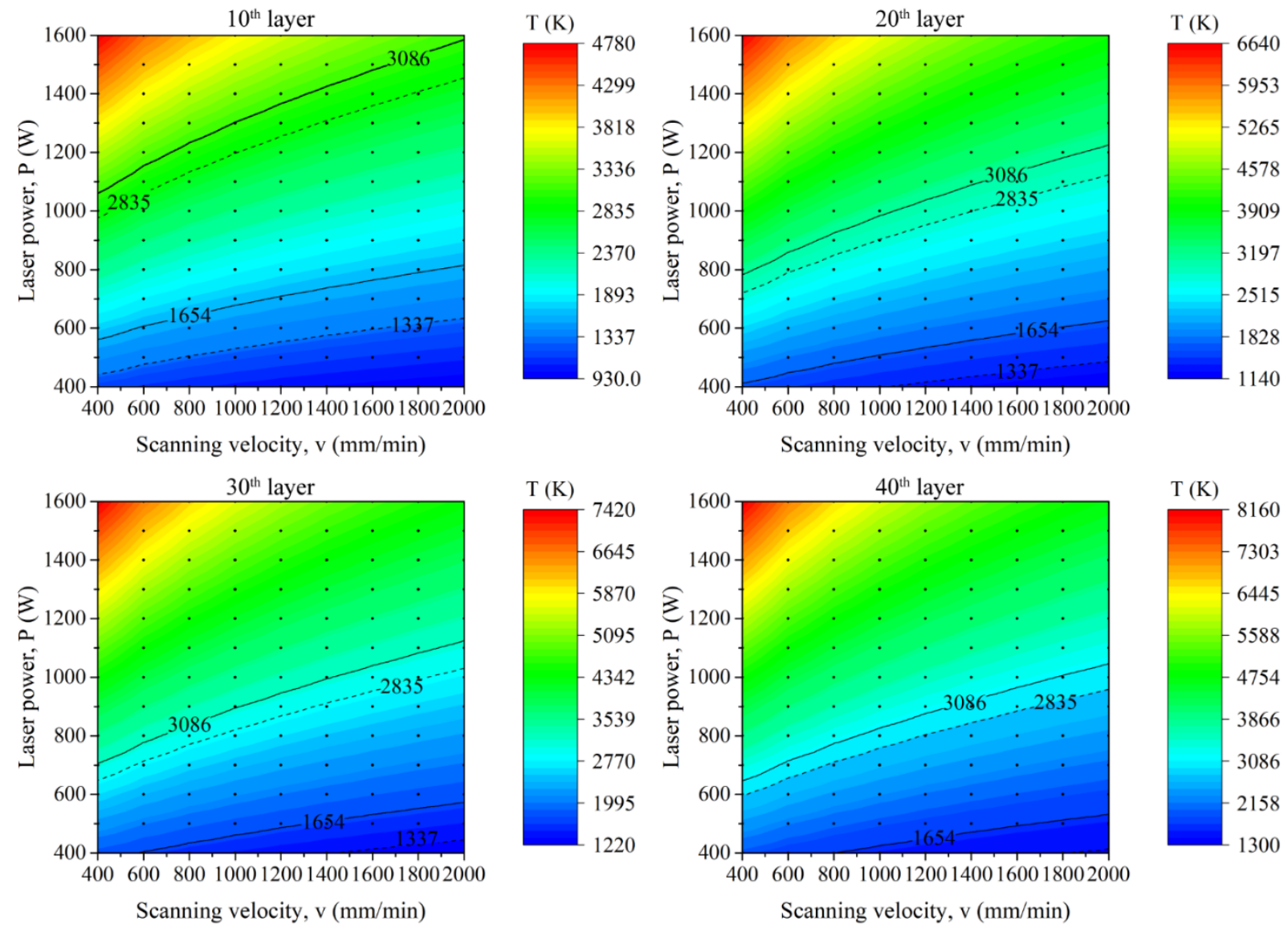

Figure 9. The peak temperature of different parameters for the 10th to 40th layers.

Figure 10 shows the optimal laser power maps dependent on the layer number when fixing the scanning velocity and hatching space. The range of laser power $(\Delta \mathrm{P})$ for a certain scanning velocity is defined as $\Delta \mathrm{P}=\mathrm{P}_{\max }-\mathrm{P}_{\min }$ to evaluate the parameter range, where $\mathrm{P}_{\max }$ and $\mathrm{P}_{\min }$ represent the maximum and minimum laser power for the printability range. The scanning velocities ranging from 800 to $1200 \mathrm{~mm} / \mathrm{min}$ are selected for the consideration of both the fabrication efficiency and the stability of powder feeding. It can be seen that the laser power changes in a large range as the layer number increases. Taking the scanning velocity of $800 \mathrm{~mm} / \mathrm{min}$ as an example, the laser power should be in the range of 1920 to $3316 \mathrm{~W}$ for the first layer, and 384 to $773 \mathrm{~W}$ for the 40 th layer. The decline rate of $\mathrm{P}_{\max }$ and $\mathrm{P}_{\min }$ is as high as 77 and $88 \%$ from the first layer to the 40 th layer. Furthermore, the $\mathrm{P}_{\max }$ and $P_{\min }$ decrease drastically for the first ten layers with the decline rate of 63 and $66 \%$ as the layer number increases and decreases slowly from the 10th to the 40th layer with the decline rate of 37 and $40 \%$. In addition, Figure 10 also reveals a sharp fall of $\Delta \mathrm{P}$ for the first ten layers and then a slight decline after ten layers, which corresponds to the variation of effective thermal conductivity with the number of layers from Figure $6 \mathrm{a}$. The $\Delta \mathrm{P}$ is $1395 \mathrm{~W}$ for the first layer and $389 \mathrm{~W}$ for the 40 th layer with a decline rate of $72 \%$. Compared to the high effective thermal conductivity for the first ten layers, the peak temperature response is more sensitive to the relatively low effective thermal conductivity because the energy can be conducted away quickly for the high effective thermal conductivity. 

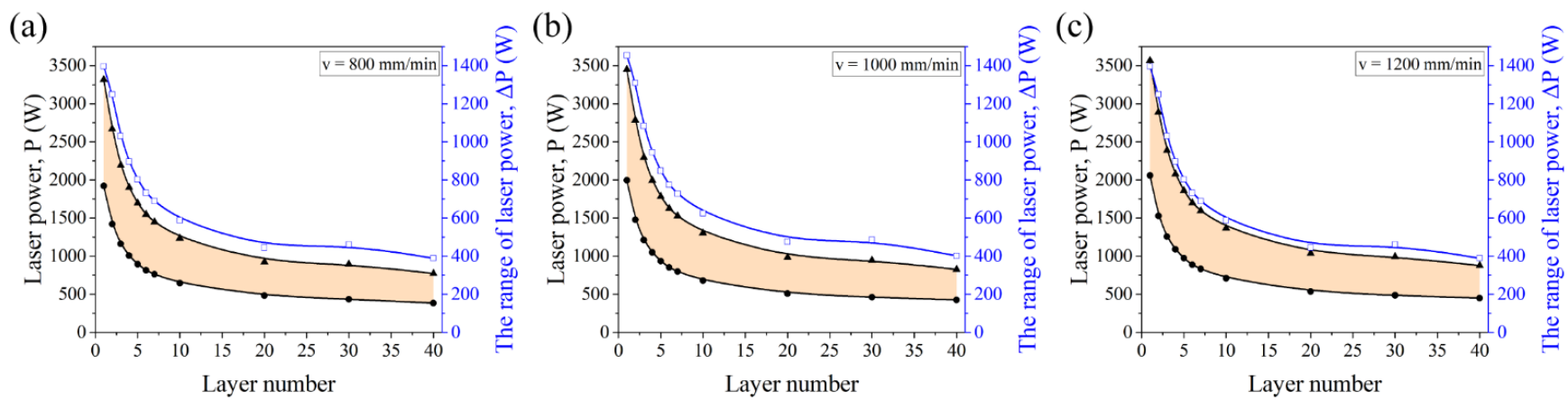

Figure 10. The variation and range of laser power with the layer number at different scanning velocities: (a) $\mathrm{v}=800 \mathrm{~mm} / \mathrm{min} ;(\mathbf{b}) \mathrm{v}=1000 \mathrm{~mm} / \mathrm{min}$, and (c) $\mathrm{v}=1200 \mathrm{~mm} / \mathrm{min}$.

\section{Verifications}

\subsection{Experiments}

The initial material was self-developed martensite stainless steel (07Cr15Ni5). The argon gas atomized spherical steel powder has the average diameter of $28.9 \mu \mathrm{m}$. The $\mathrm{CuCr}$ alloy substrate with dimensions of $135 \mathrm{~mm} \times 180 \mathrm{~mm} \times 6 \mathrm{~mm}$ was rolled $\left(900 \sim 950{ }^{\circ} \mathrm{C}\right)$ and annealed $\left(400 \sim 450{ }^{\circ} \mathrm{C}\right)$ in the experiment. The chemical composition (wt.\%) of the $\mathrm{CuCr}$ alloy substrate is $99.5 \mathrm{Cu}$ and $0.5 \mathrm{Cr}$. The substrate surfaces were roughened, sandblasted, and cleaned with alcohol before the experiment. The DED system includes a $6 \mathrm{~kW}$ IPG YLR-6000 fiber laser (IPG laser GmbH, Burbach, Germany) with the beam size of $1 \mathrm{~mm}$, a 6-axis robot, a powder feeder (HUST-III), and a self-made laser head. The 6-axis robot controls the movement of the laser head along the $\mathrm{X}-\mathrm{Y}$ plane and/or the $\mathrm{Z}$ direction. The deposition area is protected from oxidation by the argon shielding gas. Details about the DED system have also been described previously $[3,53]$. The cross-section specimen was mechanically polished and then etched by a solution of $2 \mathrm{~mL} \mathrm{HF}, 8 \mathrm{~mL} \mathrm{HNO}$, and $90 \mathrm{~mL}$ $\mathrm{H}_{2} \mathrm{O}$ at room temperature to reveal the morphology of the multi-layer steel coatings.

\subsection{Verification of the Single-Track Molten Pool Width}

Due to the high energy input during the DED process, the temperature is difficult to measure directly. The molten pool widths are generally used for verification in thermal analysis, which is frequently adopted for the DED and SLM processes [54,55]. The molten pool width is obtained by the isothermal curves of the calculation according to the melting temperature of steel $(1654 \mathrm{~K})$ as depicted in Figure 3. Table 3 shows the processing parameters used for the single track.

Table 3. Processing parameters for the single track.

\begin{tabular}{cc}
\hline Parameters & Values \\
\hline Laser power $(\mathrm{P}, \mathrm{W})$ & $3000 \sim 3600(200$ increment $)$ \\
Scanning velocity $(\mathrm{V}, \mathrm{mm} / \mathrm{min})$ & $800 \sim 1600(200$ increment $)$ \\
Powder feeding rate $(\mathrm{g} / \mathrm{min})$ & 12 \\
Laser spot diameter $(\mathrm{mm})$ & 1 \\
\hline
\end{tabular}

As shown in Figure 11, the calculated molten pool width matches well with the experimental measurements. Both the calculated and experiment results show that the molten pool width decreases as the scanning velocity increases. According to Equations (9) and (10), the increasing scanning velocity reduces particle catchment efficiency, hence the energy delivered by powder to the substrate is reduced. On the other hand, high scanning velocity means a shorter contact duration of the laser with the substrate, therefore, less energy is absorbed directly by the substrate. As a result, the molten pool width decreases with the scanning velocity. Since heat loss by the molten pool flow and the latent heat of fusion are not taken into account, the calculated widths are slightly higher than the 
experimental measurements. However, the maximum relative error is $18.59 \%$, which demonstrates the accuracy of the thermal model.
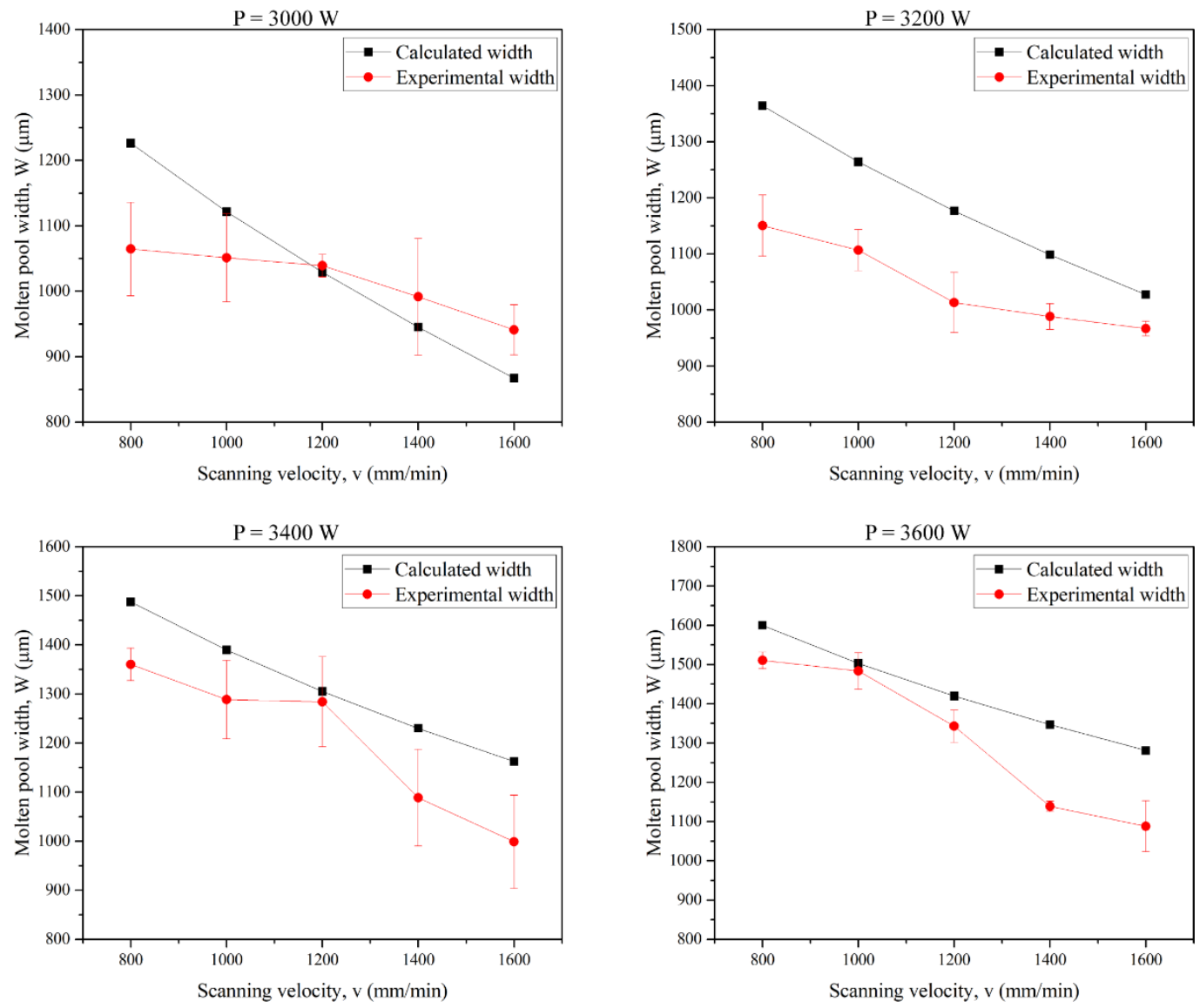

Figure 11. Comparison of experiment and calculated values of the single-track molten pool width.

\subsection{Verification of Printability Maps for the First Layer}

To verify the analytical model for the first layer, the laser scanning velocity was fixed at $800 \mathrm{~mm} / \mathrm{min}$ and the scanning patch at $0.3 \mathrm{~mm}$. As illustrated in Figure 12, the influence of laser power on the solidification behavior of the fusion track was investigated. Because of the inadequate energy, no scanning track emerged on the substrate when the laser power was $1500 \mathrm{~W}$. Fusion layers can be observed when the laser power is higher than 2000 W. As shown from the cross-section of the first layer in Figure 13, the fusion tracks are formed in the conduction mode with laser power of $2500 \mathrm{~W} \sim 3500 \mathrm{~W}$, and the morphology is uniform. When increasing the laser power to $4000 \mathrm{~W} \sim 5000 \mathrm{~W}$, the fusion tracks are formed in the keyhole mode with heterogeneous morphology. According to the calculated results above, fusion tracks can be formed in the conduction mode with the laser power of $1920 \mathrm{~W} 3316 \mathrm{~W}$ at the fixed scanning speed of $800 \mathrm{~mm} / \mathrm{min}$. The molten pool should be the keyhole mode with the laser power of above $3316 \mathrm{~W}$. However, from the cross-section morphology in Figure 13, conduction mode is observed when the laser power is $3500 \mathrm{~W}$. Because heat loss by the molten pool flow and the latent heat of fusion is not taken into account, the peak temperatures may be overpredicted slightly. 


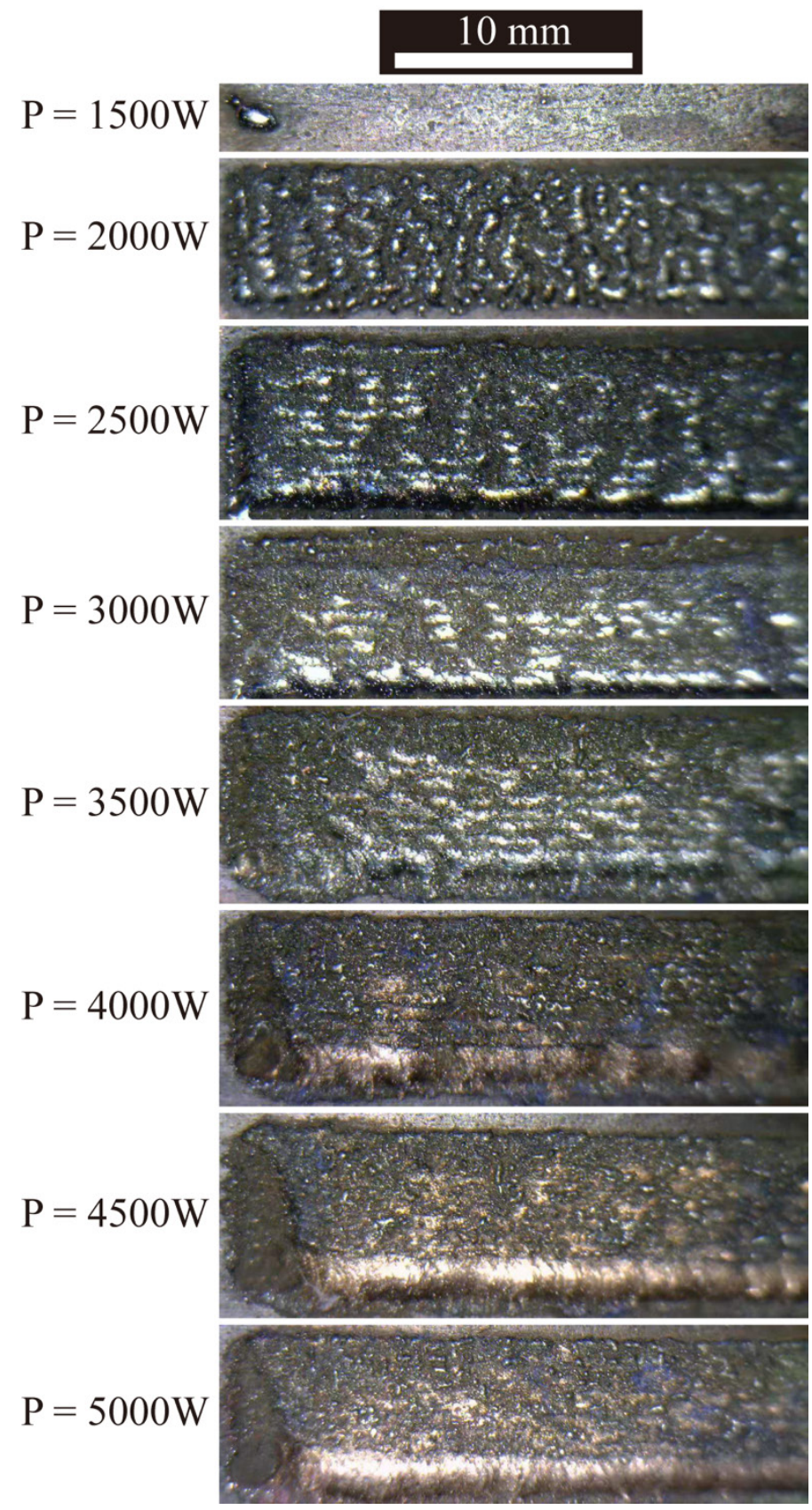

Figure 12. Surface morphologies of the single-layer specimens.

According to the experimental results shown in Figure 13, although the molten pool can be formed at 2000 to $3500 \mathrm{~W}$, the forming quality is still different. When $\mathrm{P}=2000 \mathrm{~W}$, the laser energy is too low and the fused layer cannot be formed continuously. When the laser power $\mathrm{P}=2500 \mathrm{~W}$, holes can be observed near the interface with fusion in place. When the laser power is increased to $\mathrm{P}=3000 \mathrm{~W}$, the molten layer can be well formed and no cracks are produced with the flat and straight copper-steel interface, and no obvious semi-elliptical molten pool is seen, which means the melting area is small. When the laser power increases to $\mathrm{P}=3500 \mathrm{~W}$, a semi-elliptical molten pool can be observed at the interface and cracks can be observed. It should be noted that this model can only predict formability and narrow the range of experimental parameters before conducting experiments, while defects such as cracks cannot be predicted and further experimental studies are needed. 

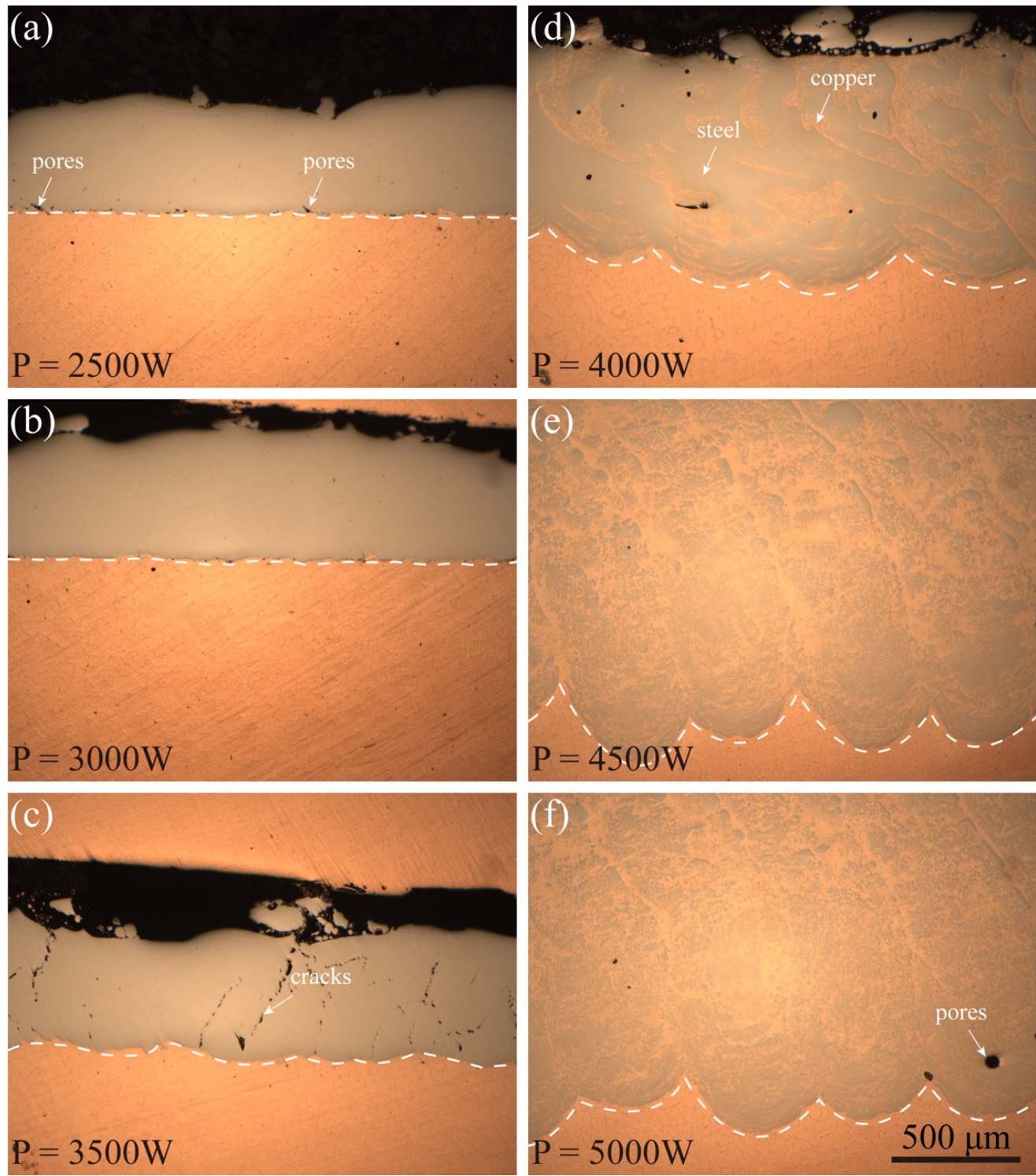

Figure 13. Cross-section morphologies of the single-layer specimens at different laser power: (a) $\mathrm{P}=2500 \mathrm{~W}$, (b) $\mathrm{P}=3000 \mathrm{~W}$, (c) $\mathrm{P}=3500 \mathrm{~W}$, (d) $\mathrm{P}=4000 \mathrm{~W}$, (e) $\mathrm{P}=4500 \mathrm{~W}$, and (f) $\mathrm{P}=5000 \mathrm{~W}$.

\subsection{Verification of Printability Maps for Multi-Layer}

The seven-layer specimen was fabricated based on the calculated results. The parameters used for the seven-layer specimen and bulk specimen are listed in Table 4. Figure 14a shows the cross-section morphologies of the seven-layer specimen. It should be noted that because the copper/steel interface with the mixed Cu-rich phase and Fe-rich phase is more sensitive to the etching agent, the aggressively etched areas at the interface will look like pores. In fact, the fabricated specimen is free of obvious defects, which can be confirmed compared with the unetched sample without obvious defects at the interface from Figure 13b. The interface of the copper/steel shown in Figure 14b indicates that a good copper/steel interface without cracks was obtained. Furthermore, the 40-layer bulk specimen with dimensions of about $70 \times 8 \times 12 \mathrm{~mm}^{3}$ was fabricated as shown in Figure 15. 
Table 4. Processing parameters used for the seven-layer and bulk specimen.

\begin{tabular}{ccc}
\hline Layer Number & Laser Power $(\mathbf{P}, \mathbf{W})$ & Scanning Velocity $(\mathbf{V}, \mathbf{m m} / \mathbf{m i n})$ \\
\hline 1 & 3000 & 800 \\
2 & 2600 & 1000 \\
3 & 2200 & 1000 \\
4 & 1900 & 1000 \\
5 & 1700 & 1000 \\
6 & 1600 & 1000 \\
7 & 1500 & 1000 \\
10 & 1300 & 1000 \\
20 & 950 & 1000 \\
30 & 900 & 1000 \\
40 & 800 & 1000 \\
\hline
\end{tabular}
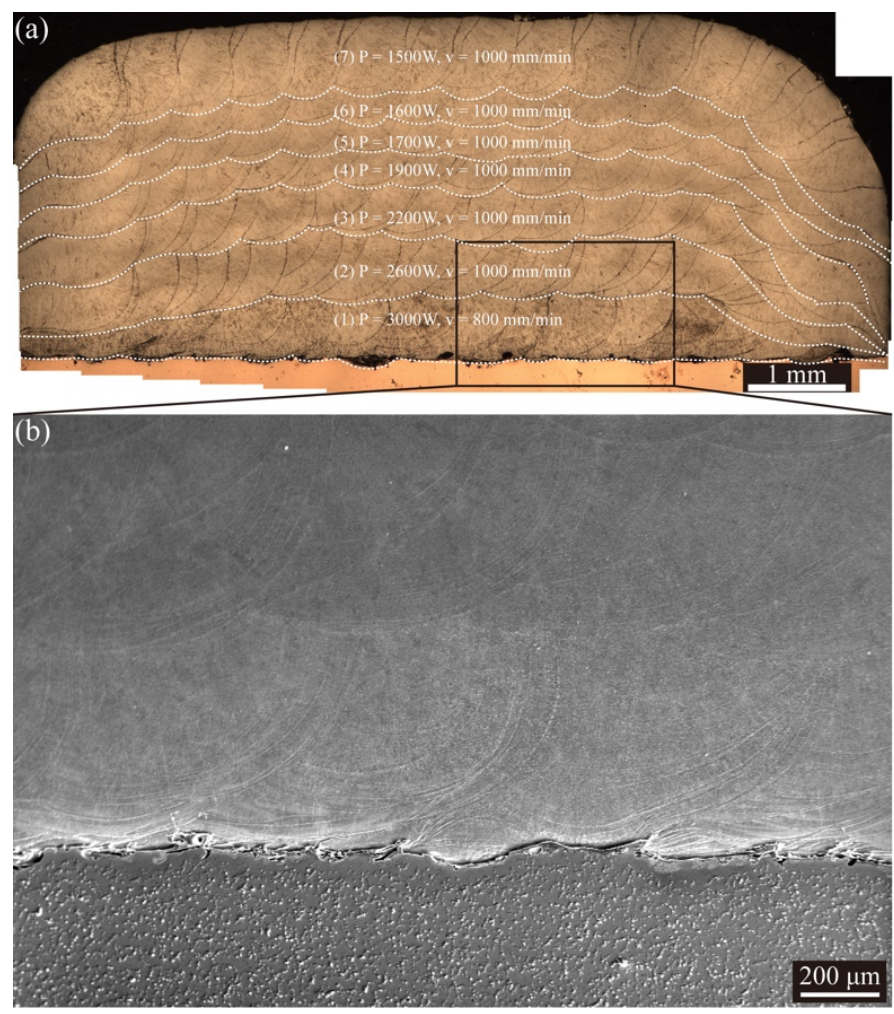

Figure 14. Cross-section morphologies of the seven-layer specimen: (a) overview of the cross-section; (b) magnified view of the copper/steel interface.

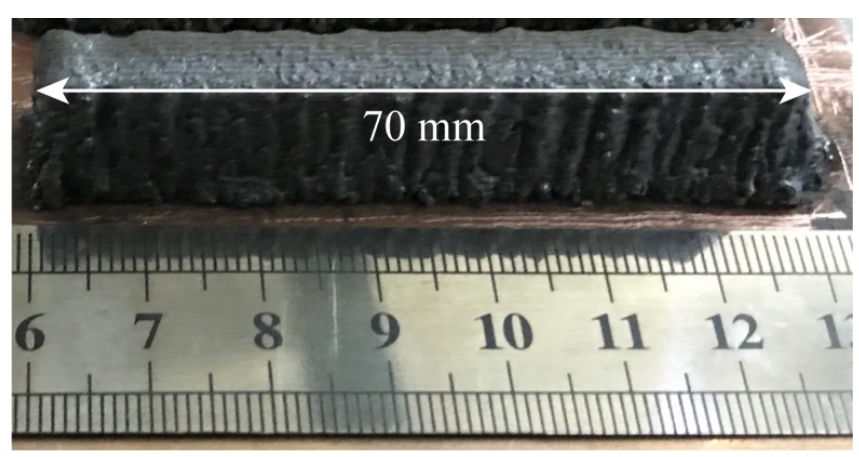

Figure 15. Morphology of the bulk specimen. 


\section{Conclusions}

A layer-dependent analytical model is established to predict the layer-dependent processing parameters when fabricating the $07 \mathrm{Cr} 15 \mathrm{Ni} 5$ steel on the $\mathrm{CuCr}$ substrate at the fixed layer thickness $(0.3 \mathrm{~mm})$ and hatching space $(0.3 \mathrm{~mm})$ and agrees well with experiments. Based on the research, the main conclusions can be drawn as follows:

(1) Considering both the great difference in thermophysical properties between copper and steel and the layer-based fabrication character of the AM process, the evolution of the effective thermophysical properties, including the effective thermal conductivity, effective density, and effective specific heat capacity with layer number are calculated. Meanwhile, the changes in absorption rate and catchment efficiency with the processing parameters are also taken into account. Then the layer-dependent effective material properties and processing parameters are provided to the Cline-Anthony thermal model. Thus, the layer-dependent analytical model is established.

(2) The model is applied to predict the printability maps as the deposition layer increases. The laser power decreases drastically for the first ten layers as the layer number increases and decreases slowly from the 10th to the 40th layer when other processing parameters are fixed. The decline rate of the maximum and minimum laser power for the printability range is as high as 77 and $88 \%$ from the first layer to the 40th layer at the scanning velocity of $800 \mathrm{~mm} / \mathrm{min}$. In addition, the $\Delta \mathrm{P}$ is $1395 \mathrm{~W}$ for the first layer and $389 \mathrm{~W}$ for the 40 th layer with a decline rate of $72 \%$. The significant narrowing of the printability maps with the layer number is due to the decreases in effective thermal conductivity and effective specific heat capacity as well as the increase in effective density.

(3) The calculated results based on the proposed analytical model agree well with the experiments. The maximum relative error for the single-track molten pool width between the calculated and experimental results is $18.59 \%$. Furthermore, the calculated formability of the first layer and multi-layer is in agreement with the experiment. The defects-free bulk specimen with dimensions of about $70 \times 8 \times 12 \mathrm{~mm}^{3}$ is successfully fabricated according to the predicted printability maps.

The proposed analytical model provides a new guidance to determine the processing windows for novel multi-material components, especially for the multi-materials whose physical properties are significantly different. Nevertheless, the criterion for the good fusion tracks is based on the peak temperature of the molten pool in the range of $\mathrm{T}_{\mathrm{s}_{\_} \text {steel }} \sim \mathrm{T}_{\mathrm{b} \_ \text {steel }}$, which may not be a precise condition to determine the final process maps. More rigorous criteria related to molten pool defects such as pores and balling formation are to be identified to further narrow the process map. Furthermore, $\mathrm{HS}$ and $\mathrm{m}_{\mathrm{p}}$ also have a significant impact on printability during the fabrication of multi-material components, which will be discussed in the future.

Author Contributions: Conceptualization, methodology, and writing —original draft preparation, W.Z.; investigation, B.Z. and H.X.; writing-review and editing, project administration, H.Z.; funding acquisition, H.Y. and Y.W.; All authors have read and agreed to the published version of the manuscript.

Funding: This work is supported by the Human Spaceflight Program of China (D050302) and the Military Industry Stability Support project (2019KGW.YY4007Tm).

Acknowledgments: The authors would like to thank the Analytical and Testing Center of HUST for the SEM analysis and Jing Li for writing assistance.

Conflicts of Interest: The authors declare no conflict of interest. 


\section{References}

1. Blakey-Milner, B.; Gradl, P.; Snedden, G.; Brooks, M.; Pitot, J.; Lopez, E.; Leary, M.; Berto, F.; du Plessis, A. Metal additive manufacturing in aerospace: A review. Mater. Des. 2021, 209, 110008. [CrossRef]

2. Gu, D.; Shi, X.; Poprawe, R.; Bourell, D.L.; Setchi, R.; Zhu, J. Material-structure-performance integrated laser-metal additive manufacturing. Science 2021, 372, 6545. [CrossRef]

3. Zhang, W.; Liao, H.; Hu, Z.; Zhang, S.; Chen, B.; Yang, H.; Wang, Y.; Zhu, H. Interfacial characteristics and mechanical properties of additive manufacturing martensite stainless steel on the $\mathrm{Cu}-\mathrm{Cr}$ alloy substrate by directed energy deposition. J. Mater. Sci. Technol. 2021, 90, 121-132. [CrossRef]

4. Kar, J.; Roy, S.K.; Roy, G.G. Effect of beam oscillation on electron beam welding of copper with AISI-304 stainless steel. J. Mater. Process. Technol. 2016, 233, 174-185. [CrossRef]

5. Liao, H.L.; Zhu, H.H.; Xue, G.; Zeng, X.Y. Alumina loss mechanism of $\mathrm{Al}_{2} \mathrm{O}_{3}$ - $\mathrm{AlSi}_{10} \mathrm{Mg}$ composites during selective laser melting. J. Alloys Compd. 2019, 785, 286-295. [CrossRef]

6. Zhang, X.C.; Pan, T.; Flood, A.; Chen, Y.T.; Zhang, Y.L.; Liou, F. Investigation of copper/stainless steel multi-metallic materials fabricated by laser metal deposition. Mater. Sci. Eng. A 2021, 811, 141071. [CrossRef]

7. Zhu, H.H.; Fuh, J.Y.H.; Lu, L. Microstructural evolution in direct laser sintering of Cu-based metal powder. Rapid Prototyp. J. 2005, 11, 74-81. [CrossRef]

8. Dávila, J.L.; Neto, P.I.; Noritomi, P.Y.; Coelho, R.T.; da Silva, J.V.L. Hybrid manufacturing: A review of the synergy between directed energy deposition and subtractive processes. Int. J. Adv. Manuf. Technol. 2020, 110, 3377-3390. [CrossRef]

9. Wang, X.; Lei, L.; Yu, H. A Review on Microstructural Features and Mechanical Properties of Wheels/Rails Cladded by Laser Cladding. Micromachines 2021, 12, 152. [CrossRef]

10. Xue, L.; Atli, K.C.; Picak, S.; Zhang, C.; Zhang, B.; Elwany, A.; Arroyave, R.; Karaman, I. Controlling Martensitic Transformation Characteristics in Defect-Free NiTi Shape Memory Alloys Fabricated Using Laser Powder Bed Fusion and a Process Optimization Framework. Acta Mater. 2021, 5, 117017. [CrossRef]

11. Yin, J.; Wang, D.Z.; Wei, H.L.; Yang, L.L.; Ke, L.D.; Hu, M.Y.; Xiong, W.; Wang, G.Q.; Zhu, H.H.; Zeng, X.Y. Dual-beam laser-matter interaction at overlap region during multi-laser powder bed fusion manufacturing. Addit. Manuf. 2021, 46, 102178. [CrossRef]

12. Yin, J.; Zhang, W.Q.; Ke, L.D.; Wei, H.L.; Wang, D.Z.; Yang, L.L.; Zhu, H.H.; Dong, P.; Wang, G.Q.; Zeng, X.Y. Vaporization of alloying elements and explosion behavior during laser powder bed fusion of Cu-10Zn alloy. Int. J. Mach. Tools Manuf. 2021, 161, 103686. [CrossRef]

13. Zhang, S.S.; Zhu, H.H.; Zhang, L.; Zhang, W.Q.; Yang, H.Q.; Zeng, X.Y. Microstructure and properties of high strength and high conductivity $\mathrm{Cu}-\mathrm{Cr}$ alloy components fabricated by high power selective laser melting. Mater. Lett. 2019, 237, 306-309. [CrossRef]

14. Zhu, H.H.; Lu, L.; Fuh, J.Y.H.; Wu, C.C. Effect of braze flux on direct laser sintering Cu-based metal powder. Mater. Des. 2006, 27, 166-170. [CrossRef]

15. Seede, R.; Shoukr, D.; Zhang, B.; Whitt, A.; Gibbons, S.; Flater, P.; Elwany, A.; Arroyave, R.; Karaman, I. An ultra-high strength martensitic steel fabricated using selective laser melting additive manufacturing: Densification, microstructure, and mechanical properties. Acta Mater. 2020, 186, 199-214. [CrossRef]

16. Craig, O.; Bois-Brochu, A.; Plucknett, K. Geometry and surface characteristics of H13 hot-work tool steel manufactured using laser-directed energy deposition. Int. J. Adv. Manuf. Technol. 2021, 116, 699-718. [CrossRef]

17. Goll, D.; Trauter, F.; Loeffler, R.; Gross, T.; Schneider, G. Additive Manufacturing of Textured FePrCuB Permanent Magnets. Micromachines 2021, 12, 1056. [CrossRef]

18. Kozior, T.; Bochnia, J. The Influence of Printing Orientation on Surface Texture Parameters in Powder Bed Fusion Technology with 316L Steel. Micromachines 2020, 11, 639. [CrossRef]

19. Keist, J.S.; Nayir, S.; Palmer, T.A. Impact of hot isostatic pressing on the mechanical and microstructural properties of additively manufactured Ti-6Al-4V fabricated using directed energy deposition. Mater. Sci. Eng. A 2020, 787, 139454. [CrossRef]

20. Xue, A.T.; Lin, X.; Wang, L.L.; Wang, J.; Huang, W.D. Influence of trace boron addition on microstructure, tensile properties and their anisotropy of Ti6Al4V fabricated by laser directed energy deposition. Mater. Des. 2019, 181, 107943. [CrossRef]

21. Tan, H.; Guo, M.L.; Clare, A.T.; Lin, X.; Chen, J.; Huang, W.D. Microstructure and properties of Ti-6Al-4V fabricated by low-power pulsed laser directed energy deposition. J. Mater. Sci. Technol. 2019, 35, 2027-2037. [CrossRef]

22. Hu, Z.H.; Zhu, H.H.; Zhang, C.C.; Zhang, H.; Qi, T.; Zeng, X.Y. Contact angle evolution during selective laser melting. Mater. Des. 2018, 139, 304-313. [CrossRef]

23. Zhang, W.Q.; Zhu, H.H.; Hu, Z.H.; Zeng, X.Y. Study on the Selective Laser Melting of AlSi10Mg. Acta Metall. Sin. 2017, 53, 918-926.

24. Caiazzo, F.; Alfieri, V.; Bolelli, G. Residual stress in laser-based directed energy deposition of aluminum alloy 2024: Simulation and validation. Int. J. Adv. Manuf. Technol. 2021, 1-15. [CrossRef]

25. Karg, M.C.H.; Ahuja, B.; Wiesenmayer, S.; Kuryntsev, S.V.; Schmidt, M. Effects of Process Conditions on the Mechanical Behavior of Aluminium Wrought Alloy EN AW-2219 (AlCu6Mn) Additively Manufactured by Laser Beam Melting in Powder Bed. Micromachines 2017, 8, 23. [CrossRef]

26. Yin, J.; Yang, L.L.; Yang, X.; Zhu, H.H.; Wang, D.Z.; Ke, L.D.; Wang, Z.M.; Wang, G.Q.; Zeng, X.Y. High-power laser-matter interaction during laser powder bed fusion. Addit. Manuf. 2019, 29, 100778. [CrossRef] 
27. Gokcekaya, O.; Ishimoto, T.; Hibino, S.; Yasutomi, J.; Narushima, T.; Nakano, T. Unique crystallographic texture formation in Inconel 718 by laser powder bed fusion and its effect on mechanical anisotropy. Acta Mater. 2021, 212, 116876. [CrossRef]

28. Bai, Y.C.; Zhang, J.Y.; Zhao, C.L.; Li, C.J.; Wang, H. Dual interfacial characterization and property in multi-material selective laser melting of 316L stainless steel and C52400 copper alloy. Mater. Charact. 2020, 167, 110489. [CrossRef]

29. Liu, Z.H.; Zhang, D.Q.; Sing, S.L.; Chua, C.K.; Loh, L.E. Interfacial characterization of SLM parts in multi-material processing: Metallurgical diffusion between 316L stainless steel and C18400 copper alloy. Mater. Charact. 2014, 94, 116-125. [CrossRef]

30. Chen, J.; Yang, Y.Q.; Song, C.H.; Zhang, M.K.; Wu, S.B.; Wang, D. Interfacial microstructure and mechanical. properties of 316L /CuSn10 multi-material bimetallic structure fabricated by selective laser melting. Mater. Sci. Eng. A 2019, 752, 75-85. [CrossRef]

31. Chen, J.; Yang, Y.Q.; Song, C.H.; Wang, D.; Wu, S.B.; Zhang, M.K. Influence mechanism of process parameters on the interfacial characterization of selective laser melting 316L/CuSn10. Mater. Sci. Eng. A 2020, 792, 139316. [CrossRef]

32. Tan, C.L.; Zhou, K.S.; Ma, W.Y.; Min, L. Interfacial characteristic and mechanical performance of maraging steel-copper functional bimetal produced by selective laser melting based hybrid manufacture. Mater. Des. 2018, 155, 77-85. [CrossRef]

33. Wei, H.L.; Mukherjee, T.; Zhang, W.; Zuback, J.S.; Knapp, G.L.; De, A.; DebRoy, T. Mechanistic models for additive manufacturing of metallic components. Prog. Mater. Sci. 2021, 116, 100703. [CrossRef]

34. Zeng, K.; Pal, D.; Teng, C.; Stucker, B.E. Evaluations of effective thermal conductivity of support structures in selective laser melting. Addit. Manuf. 2015, 6, 67-73. [CrossRef]

35. Knapp, G.L.; Mukherjee, T.; Zuback, J.S.; Wei, H.L.; Palmer, T.A.; De, A.; DebRoy, T. Building blocks for a digital twin of additive manufacturing. Acta Mater. 2017, 135, 390-399. [CrossRef]

36. Tran, H.C.; Lo, Y.L. Systematic approach for determining optimal processing parameters to produce parts with high density in selective laser melting process. Int. J. Adv. Manuf. Technol. 2019, 105, 4443-4460. [CrossRef]

37. Cline, H.E.; Anthony, T.R. Heat treating and melting material with a scanning laser or electron beam. J. Appl. Phys. 1977, 48, 3895-3900. [CrossRef]

38. Picasso, M.; Marsden, C.F.; Wagniere, J.D.; Frenk, A.; Rappaz, M. A simple but realistic model for laser cladding. Metall. Mater. Trans. B 1994, 25, 281-291. [CrossRef]

39. Ahsan, M.N.; Pinkerton, A.J.; Moat, R.J.; Shackleton, J. A comparative study of laser direct metal deposition characteristics using gas and plasma-atomized Ti-6Al-4V powders. Mater. Sci. Eng. A 2011, 528, 7648-7657. [CrossRef]

40. Tabernero, I.; Lamikiz, A.; Martinez, S.; Ukar, E.; de Lacalle, L.N.L. Modelling of energy attenuation due to powder flow-laser beam interaction during laser cladding process. J. Mater. Process. Technol. 2012, 212, 516-522. [CrossRef]

41. Zhang, X.C.; Pan, T.; Chen, Y.T.; Li, L.; Zhang, Y.L.; Liou, F. Additive manufacturing of copper-stainless steel hybrid components using laser-aided directed energy deposition. J. Mater. Sci. Technol. 2021, 80, 100-116. [CrossRef]

42. Onuike, B.; Heer, B.; Bandyopadhyay, A. Additive manufacturing of Inconel 718-Copper alloy bimetallic structure using laser engineered net shaping (LENS (TM)). Addit. Manuf. 2018, 21, 133-140.

43. Velu, M.; Bhat, S. Metallurgical and mechanical examinations of steel-copper joints arc welded using bronze and nickel-base superalloy filler materials. Mater. Des. 2013, 47, 793-809. [CrossRef]

44. Ready, J.F.; Farson, D.F.; Feeley, T. LIA Handbook of Laser Materials Processing; Springer: Berlin/Heidelberg, Germany, $2001 ;$ p. 715.

45. Jadhav, S.D.; Goossens, L.R.; Kinds, Y.; Hooreweder, B.V.; Vanmeensel, K. Laser-based powder bed fusion additive manufacturing of pure copper. Addit. Manuf. 2021, 42, 101990. [CrossRef]

46. Wei, C.; Gu, H.; Li, Q.; Sun, Z.; Chueh, Y.-H.; Liu, Z.; Li, L. Understanding of process and material behaviours in additive manufacturing of Invar36/Cu10Sn multiple material components via laser-based powder bed fusion. Addit. Manuf. 2020, 37, 101683. [CrossRef]

47. Khairallah, S.A.; Anderson, A.T.; Rubenchik, A.; King, W.E. Laser powder-bed fusion additive manufacturing: Physics of complex melt flow and formation mechanisms of pores, spatter, and denudation zones. Acta Mater. 2016, 108, 36-45. [CrossRef]

48. King, W.E.; Barth, H.D.; Castillo, V.M.; Gallegos, G.F.; Gibbs, J.W.; Hahn, D.E.; Kamath, C.; Rubenchik, A.M. Observation of keyhole-mode laser melting in laser powder-bed fusion additive manufacturing. J. Mater. Process. Technol. 2014, 214, $2915-2925$. [CrossRef]

49. Guo, C.; Xu, Z.; Zhou, Y.; Shi, S.; Li, G.; Lu, H.; Zhu, Q.; Ward, R.M. Single-track investigation of IN738LC superalloy fabricated by laser powder bed fusion: Track morphology, bead characteristics and part quality. J. Mater. Process. Technol. 2021, $290,117000$. [CrossRef]

50. Yin, J.; Wang, D.Z.; Yang, L.L.; Wei, H.L.; Dong, P.; Ke, L.D.; Wang, G.Q.; Zhu, H.H.; Zeng, X.Y. Correlation between forming quality and spatter dynamics in laser powder bed fusion. Addit. Manuf. 2020, 31, 100958. [CrossRef]

51. Shao, J.; Yu, G.; He, X.; Li, S.; Li, Z.; Wang, X. Process maps and optimal processing windows based on three-dimensional morphological characteristics in laser directed energy deposition of Ni-based alloy. Opt. Laser Technol. 2021, $142,107162$. [CrossRef]

52. Tran, H.C.; Lo, Y.L.; Le, T.N.; Lau, A.K.T.; Lin, H.Y. Multi-scale simulation approach for identifying optimal parameters for fabrication of high-density Inconel 718 parts using selective laser melting. Rapid Prototyp. J. 2021. ahead-of-print. [CrossRef]

53. Wang, D.Z.; Hu, Q.W.; Zeng, X.Y. Residual stress and cracking behaviors of Cr13Ni5Si2 based composite coatings prepared by laser-induction hybrid cladding. Surf. Coat. Technol. 2015, 274, 51-59. [CrossRef] 
54. Siao, Y.-H.; Wen, C.-D. Examination of molten pool with Marangoni flow and evaporation effect by simulation and experiment in selective laser melting. Int. Commun. Heat Mass Transf. 2021, 125, 105325. [CrossRef]

55. Chen, C.P.; Yin, J.; Zhu, H.H.; Xiao, Z.X.; Zhang, L.; Zeng, X.Y. Effect of overlap rate and pattern on residual stress in selective laser melting. Int. J. Mach. Tools Manuf. 2019, 145, 103433. [CrossRef] 